\title{
El Empresario
}

\section{Reflexiones sobre la función empresarial en la sociedad}

\section{Henrique Urbano}

Para el profano, adentrarse en el mundo empresarial es remover un cajón de sorpresas. Los empresarios tienen una imagen. La más difundida es la de personas que comparten en sesiones y asociaciones sesudas horas de animados conversatorios sobre la marcha de los negocios, las políticas económicas y financieras, los gemidos secretos de las empresas. Si nos atenemos a esa imagen grave y severa que sugiere todo el peso del mundo financiero tendríamos que admitir que no hay mundo más consciente de la importancia, de la responsabilidad pública y del bien común que esa élite de negocios, miembros de clubes y de asociaciones casi secretas 0 , por lo menos, rigurosamente selectivas.

A la imagen fría y austera que difunden los medios de comunicación masivos, puede oponerse la figura ostensivamente práctica y eficaz del empresario que difundieron los famosos videos de Montesinos. En ellos se dio a conocer una dimensión del quehacer empresarial a la que no faltaban pruebas fehacientes: la acción delincuente como forma de realizar negocios y de crear empresas. El espanto fue mayúsculo y el impacto psicosocial de esas imágenes tiene consecuencias imprevisibles que muy probablemente quedarán en la memoria de muchos por largo tiempo ${ }^{1}$. Por más extraño que parezca, una de las más famosas empresarias británicas, Anita Roddick, la de los Body Shops, considerada en los medios empresariales y financieros británicos durante veinte años como una de las mejores representantes de la New Economy, había llamado la atención para ese género de conductas en medios financieros y empresariales ${ }^{2}$. Importa, pues, tener presente esa dimensión del quehacer empresarial ${ }^{3}$.

Nuestra intención aquí, es explorar el contenido de la figura del empresario dentro del contexto de la sociedad contemporánea. Lo que nos obliga a encontrar los recursos metodológicos que nos permitan definirla e instrumentalizarla. Boltanski me servirá de muleta ${ }^{4}$. Al estudiar los cambios en las sociedades occidentales, opulentas en las últimas cuatro décadas, el sociólogo francés indaga acerca de los motivos que llevan a los individuos a aceptar los valores y las normas que hacen del capitalismo una forma y una razón de vivir. Porque contrariamente a lo que la opinión común afirma y los filósofos dèl liberalismo del siglo XVIII y XIX asumen, la conducta socioeconómica y financiera que se des-

\footnotetext{
I Llamó mucho la atención del público la presencia de varios empresarios en las conversaciones filmadas con Vladimiro Montesinos. lo que da cuenta de las dimensiones de la comupción en el Perú. Sobre el tema de la conupción, véase Luis Fernández Rios. Psicología de la corrupción y los corruptos. Grupo editorial universitario. Santiago de Compostela. 1999)

2 Thomas Frank. One market under God. Extreme capitalism, market populism and the end of economic democracy, Doubleday. NY. 2(0X): 245.

3 Thomas Frank subraya esta dimensión en su fascinante estudio de los medios financieros estadounidenses: leidem

4 Luc Boltanski y Eve Chiapello. Le nouvel esprit du cupitalisme, Gallimard. Paris, 1999.
} 
prende de una perspectiva de corte capitalista no obedece a una "naturaleza humana sedienta de propiedad e insaciable en su placer" (cita). Ninguna teoría psicosociológica avalaría semejantes proposiciones. Pero si por hipótesis eso fuese lo cierto, pregunta Boltanski: ¿cómo explicar entonces los evidentes éxitos alcanzados por el capitalismo contemporáneo y su innegable capacidad para sacar adelante sus propuestas? Ahora bien, una de las columnas que sostiene todo el edificio de las sociedades capitalistas actuales es precisamente el empresariado. Con él y a la sombra de su bandera, las sociedades más opulentas convencieron a indecisos y escépticos a plegarse a sus prácticas y a los argumentos que dan razón de su existencia.

\section{I.-Empresariado como práctica social contemporánea}

Refrescaré la memoria con unas cuantas observaciones acerca de la presencia y función del empresario en la sociedad contemporánea. El empresario es una pieza clave en los procesos sociales, es decir, en la construcción de una red de intercambios que transforman las sociedades en sistemas de comunicación amplios y abiertos. Entiéndase por ello las sociedades más desarrolladas como las que, por ejemplo, constituyen el G7, y las menos desarrolladas, verbi gratia, la sociedad peruana. Valga la perogrullada: en el Perú existe una sociedad que, en sus estructuras socioeconómicas, es capitalista pese a su precariedad financiera y a los sobresaltos e imprevistos que la agobian, como son, por ejemplo, el Fenómeno del Niño y la corrupción. No obstante, como en las demás, también en ella la función empresarial es llamada a desempeñar un papel preponderante. Aunque muy apagadas, algunas señales dispersas lo demuestran ${ }^{5}$.

En los últimos años se multiplicaron los centros de formación y los cursos de actualización en el campo empresarial donde no escaseó la presencia de eminentes especialistas extranjeros, sobre todo estadounidenses. Y la publicidad de las

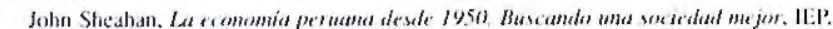

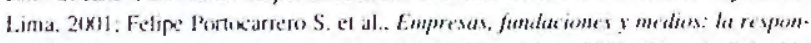
sabifidad social en el Peni. Universidad del Pacilico. Lima. 2(kn): Edtardo Sclumidt. Erica ynegerios para America Laina. Universidad del Pacilico/ OXY. Lima. $2(\mathrm{KK})$.
}

universidades y de las escuelas de negocios y empresas cubre cada mes, sino cada semana, las páginas de los periódicos nacionales con seductoras promesas de éxito empresarial ${ }^{6}$. Es decir, en medio de todos los desastres sociopolíticos y económicos que llovieron sobre la sociedad peruana en los últimos tiempos, los medios académicos mantuvieron viva la llama del interés por un sector vital para el futuro socioeconómico del país. Se debatieron los principales temas del momento, se buscaron orientaciones y se realizó un diseño de lo que es un empresario y del mundo que lo rodea. El Congreso Anual de Empresarios (CADE), tanto empresarial como juvenil, es un excelente ejemplo de ese esfuerzo ${ }^{7}$.

Ese interés creciente por el mundo empresarial se dió en medio de las posibilidades que la paz interna abrió al mundo de los negocios a partir de 1992. Asegurada la convivencia pacífica y la normalidad de las relaciones sociales, las instituciones cobraron fuerza paulatinamente y la voz de los grupos empresariales se hizo escuchar. La bonanza internacional, máxime de los Estados Unidos, ayudó a la creación de un clima propicio para la llegada de inversiones extranjeras. Las privatizaciones facilitaron las relaciones. Con ellas, el empresariado peruano pudo confiar en el futuro de sus inversiones y asegurar las condiciones de reproducción del capital. Hubo crecimiento económico, y en algunos años, con cierto sabor a una permanente condición alcista. De esta manera, el ejercicio central de la sociedad de mercado abierto recuperaba sus derechos y la función empresarial podía desarrollarse nuevamente en condiciones normales. Nada hacía prever la hecatombe fujimontesinista. Sin embargo, la experiencia empresarial de los últimos años y la presencia de inversiones extranjeras atenuó la perversidad de los efectos que hubieran podido desatarse en esas circunstancias excepcionales ${ }^{8}$.

\footnotetext{
6 Los periodicos más influyentes en les medies empresuriales como El Comercio, por ejent. phe publican cada semana el anureio de curves auto de universidades como de institutas o gnupas privados wote enpresariads. Son farticulanente insistentes la Univenidad de Ciencias Aplicadas (UTC). la Universidad del Pacition y la Univenidad de Lima, con la Exutela de Altos Negoxios (ESAN) y el laviluto Penuano de Administracion de Enpresas (IPAEI. La sección "Negoxius" de El Comercen publica cada semana aricuks de difusión de marketing que dan una ides bastante prexis del mendo de empreviral peruano.

7 En una encuesta reciente, en CADE juvenil, $73 \%$ de lox jovenes participantes, unos $5(x)$. daban muestras de contianza en el porvenir empresarial peruano (E) Conercie. It de junis $2(0) 1$. B2)

$x$ John Sheahan. op? cit.: 2022.224
} 
De esos debates y de los eventos que se llevaron a cabo, se fueron perfilando definiciones del empresario y del empresariado. La gran mayoría se adecua con las que difunden los maestros en la materia: la empresa expresa una práctica económica llevada a cabo por un individuo o porvarios individuos en vista a la obtención de ciertos objetivos de reproducción de capital ${ }^{9}$. En el contexto capitalista, los objetivos son los de la maximización de las ganancias. Siguiendo ese imperativo, la práctica empresarial desarrolla las estrategias más adecuadas para alcanza: lo que la propia existencia de la empresa señala, es ócir, la capacidad de recuperar el capital invertido dentro de límites de un calendario razonable de obtención de resultados. Precisamente la estrategia es el enunciado de decisiones que deben ser tomadas en el transcurso del tiempo, teniendo como meta alcanzar un monto razonable de beneficios, lo que en términos capitalistas debe ser entendido como el máximo posible. Ésta es la clave indispensable para entender la práctica empresarial ya que, para emplear las palabras de un especialista de la UPC, "en el mundo empresarial, el éxito de una gestión se refleja en la cantidad de dinero obtenido"10.

En torno a la definición general que acabo de dar, hay una infinita variedad de opciones y variaciones temáticas; sin embargo, la práctica empresarial aúna todas las energías en función del desarrollo económico y financiero siendo, por consiguiente, el centro de atención de toda la actividad tanto social como política. Y por ser lo que son en el desarrollo actual de las sociedades, las expresiones asociativas empresariales presentan un cuadro general de actividades muy complejo, donde se mezclan los conocimientos de expertos con los del simple obrero en el sentido clásico del término. Ese es uno de los rasgos de la empresa contemporánea, que dentro de su espacio de acción asume una gran variedad de personas, recreando bajo otras formas y expresiones, el modelo del siglo XIX donde el capital y el trabajo, la propiedad y la mano de obra, pertenecen a campos diferenciados, pero complementarios. Así, pese a los avances de la ciencia y

\footnotetext{
Una simple mirada en las páginas de algunos autores consagrados, míxime las de los matestros contemporáneos del managememf. mostraria una diversidad de opiniones sobre Ja materia. Frank menciena algenos casos donde el vocabulario pexes o nada tiene que ver con la formulación clásica de la maximización de los benélicios. Algunas metáforas actuales son sorprendentes como las del "Cannibalize yourself" "Destruction is cooll" Thomas Franck: 244.251.

16) David Fischman, El espejo del hider, UPC/El Comercio, Lima, 2(xk): 67. Una de las expresiones más difundidas es la de "cultura empresarial". Sobre ella. ver, por ejemplo, Eduardo Schmidt. op. cit: 549 - 555 .
}

de la tecnología, la separación de funciones y prácticas sociales en la producción y reproducción de riqueza obedece al principio de apropiación de bienes y servicios en una red de intercambios garantizados por las normas legales y por la fuerza del Estado.

Insistiré sobre este punto porque me parece muy importante para la comprensión del tema empresarial, sobre todo en el contexto del desarrollo presente de la sociedad peruana.

Un importante número de autores contemporáneos distingue varias fases en la evolución de las sociedades capitalistas des de el siglo XIX hasta nuestros días. En base a las clásicas investigaciones de Max Weber ${ }^{11}$ y Werner Sombart ${ }^{12}$ sobre las prácticas empresariales de la sociedad moderna, se puede afirmar que las primeras manifestaciones de la sociedad capitalista se ubican en un registro familiar o doméstico. Basta recordar la gran figura del burgués, típica expresión del siglo XIX, inmortalizada en algunos de los más notables novelistas europeos. Sombart lo analizó con más detalle y le dio contornos históricos y sociológicos precisos. EI burgués era el empresario con figura de "caballero de la industria", de innovador y conquistador, con tendencia a ser identificado como un héroe que se arriesga y se juega todo en la empresa. Era un empresario doméstico, es decir, la empresa se generaba en el ámbito familiar. No había grandes empresas o por lo menos muy pocas se podrían comparar a las que hoy conocemos. Sin embargo, en la sociedad peruana contemporánea aún persisten rasgos que nos traen a la memoria "el caballero de la industria" de los tiempos de la sociedad industrial ${ }^{13}$. El "héroe" que se levanta de la nada saca a lucir sus fueros y laureles, el "caballero honesto" que con los miembros de la familia va construyendo los cimientos de su pequeña empresa, el "emprendedor hacendoso" que todos los días suda la camiseta para producir y sacar adelante su taller, son imágenes casi cotidianas en nuestro medio. La experiencia Gamarra (Lima-Perú) fue, hasta hace poco, un símbolo de ese tipo de empresa. Pero también las hay que aún viven de rentas de viejas herencias o se van extinguiendo poco a poco con las ganancias que le

\footnotetext{
1) Max Weber, cconemista e historiador, propuso una explicación del origen del capitalismo en su lamosa ubra La ética protestante y el espínitu del cupinalismo. Istno. Madrid. $190 \times[1905]$.

12 Werner Sombart. El burgués. Connribación a la historia espirimal del hombre economico moderno (Historia Y Geografia). Alianza. Madrid. 1998 [1913].

13. Carlos Malpica, El poder económico en el Peru, 1-/I. Mosca Azul Editores, Lima. 1989.
} 
proporciona un negocio donde los productos importados permiten a los empresarios vivir holgadamente sin gastar muchas energías. En resumidas cuentas, la sociedad peruana contemporánea, como ocurre en muchas otras donde el desenvolvimiento económico y financiero es mínimo, se va acomodando a los vaivenes de la improvisación o informalidad, con algunos logros que es justo no olvidar y que veremos más adelante. De todas maneras, importa tener presente esos resabios decimonónicos del empresariado peruano actual ${ }^{14}$.

El segundo momento en el desarrollo de las sociedades capitalistas no puede ignorar el derrumbe financiero de 1929. Convengamos con los sociólogos e historiadores que lo que caracteriza esa etapa es el nacimiento del empresario comercial y las primeras manifestaciones de empresas gigantescas de corte internacional. El proceso no tiene una fecha precisa. Sin embargo, la expansión de las propias sociedades capitalistas conlleva una novedosa forma de concebir la empresa. En ella, los empresarios se desprenden de sus antiguos hábitos de "caballeros de la industria". El nombre de Taylor (1856-1915) se difunde con el modelo de organización del trabajo que lleva su nombre desde los inicios del siglo XX. Su The principles of scientific management, de 1911, domina ampliamente ese período, cruzando la Primera Guerra Mundial y proyectándose hasta la mitad del siglo ${ }^{15}$. Así, el taylorismo se instala en las empresas y el paradigma que él propone constituye la norma de referencia de toda la organización del trabajo durante gran parte del siglo XX. Sus dos grandes principios: combatir la ineficacia y el colectivismo ${ }^{16}$.

Con la Segunda Guerra Mundial se alteró la marcha de las sociedades occidentales hacia sus destinos liberales o socialistas. Y la carta geográfico-política que dejó la partición de los territorios sometidos por la guerra al Occidente y Rusia, lanzó a los países y a los grupos hacia el campo de la competición económica y financiera. Reorganizados y estructurados en dos grandes bloques, el Occidental y el Oriental europeo, el desarrollo de los dos polos se llevó a cabo con banderas opuestas, la del liberalismo y la del socialismo. En la primera con la empresa capitalista libre de las amarras del Estado y en la segunda, construyendo un aparato industrial bajo la égida del Estado. En ésta se orientan las prácticas económicas y financieras con planes quinquenales, diseñado por expertos estatales; en aquella es la ley del mercado que la dirige por caminos que sólo él conoce. La caída del muro de Berlín acabó con la primera, y la segunda se volvió triunfante y monocórdica. No obstante, las últimas cuatro décadas muestran señales de que la marcha, al interior de la frontera del libre mercado, sufrió profundos cambios, no sólo antes de que Berlín fuese el símbolo de la quiebra del Estado burocrático y emprendedor, sino también a partir de la década del 60 . De ello se pueden sacar algunas lecciones con las sugerencias que nos proporciona Boltanski a partir del análisis del caso francés.

La primera. Los años 60 producen un discurso empresarial en torno a dos ejes: el gran descontento de los profesionales o cuadros ${ }^{17}$ y la dificultad de gestión de empresas gigantes. En el primero se concentran los deseos de participación de los expertos o directores en la dirección de la empresa, rompiendo de una vez por todas con el viejo modelo de propietario-empresario e introduciendo la imagen del director-experto, del técnico; y en el segundo se manifiestan los esfuerzos por descentralizar, siendo una de las consecuencias de ese proceso la creación de la dirección por objetivos, con autonomía para los managers, aunque rígidamente dirigidos por un plan conforme a los objetivos de la empresa. Por esa época, en el Perú, asistíamos al desarrollo imparable de las fábricas de harina de pescado dirigidas por el empresario Luis Banchero, más cercano a lo que la literatura empresarial llamaría un "caballero de la industria" que a un empresario dando el brazo a torcer frente a la clase montante de los "expertos". Y la dictadura de Velasco los alejó del horizonte empresarial de libre mercado hasta los años 80 . Luego del período belaundista vino el desastre económico del gobierno de Alan García donde se desempolvaron políticas económicas y financieras que las sociedades capitalistas occidentales habían rechazado o corregido y, en la mayoría de los casos, olvidado.

\footnotetext{
14 Felipe Pontoxirrero S.. op. rit. I.ima. $2(x)$

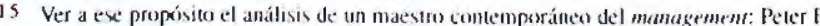

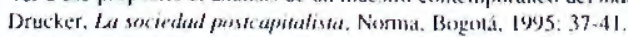

17 Hay un problema planteado por el vocabulario en las nuevas clasificaciones adminis. trativas estalales A simple vista. el uso de neevos lérminos da la impresión que se trata de un simple problena burocrático. Sin embargo, el asunto es mucho mis complejo. Y la razón es fácil de comprender: al crear nuevas clasiticaciones de personal en los sistemas administrativas se introducen cambios en la percepxión de las prácticas weiales. Boltanski analizacon bastante agudeza este kema: Lw Boltanski y Eve Chiapello, op. fii.. Gallimard. Pans, 1999) 125-140. También Paul Bouftartigue y Charles Gadea. Senciologie des cadres, la decouvene. Paris. $2(x(x): 21$ 
Cabe notar, sin embargo, el espacio abierto por los egresados de la Universidad del Pacífico y de ESAN que también desempeñaron un papel importante en la sociedad peruana cuando se abrió el horizonte político en 1980.

La segunda. Los años 90 muestran señales de cambios profundos en las orientaciones empresariales producidas por la evolución de las sociedades occidentales opulentas en lo que atañe a la gestión de negocios y prácticas financieras. Señala Boltanski la aparición del modelo que podríamos llamar empresa en red donde se expresa el rechazo de la jerarquía que escalona los expertos-managers y los que los siguen, al mismo tiempo que se hace un vibrante llamado a la aceptación de los cambios que ocurren en las sociedades actuales con rápidos movimientos de grupos, aparición de nuevas prácticas sociales y renovadas mentalidades. La empresa en red exige flexibilidad y un sentido agudo de adaptación y los más recientes portavoces de esas nuevas orientaciones empresariales cantan los méritos de la creatividad, vocablo que ignoraba la primigenia literatura del management. Precisamente, en esos términos se expresan actualmente algunos ensayos peruanos. Sirva de ejemplo el muy reciente de Liliana Galván Oré sobre la creatividad y la innovación ${ }^{18}$.

\section{II.-Empresa en red en la "ciudad de proyectos"}

Para caracterizar los nuevos paisajes de las sociedades occidentales opulentas y sus prácticas socioeconómicas, Boltanski echa mano de la idea de "proyecto", a la cual añade la expresión "ciudad de proyectos". El vocablo "proyecto" viene de la literatura del management y expresa "la acción orientada hacia el objetivo requerida para poder realizar una idea, una propuesta, un paso evolutivo, o algo parecido" 19 ; en cuanto al de "ciudad", Boltanski lo emplea para designar la sociedad que emerge a partir de la década del 90 . Sospechamos que "ciudad" es sinónimo de "sociedad"

\footnotetext{
I8 Liliana Galván Oré. Crratisidad para el cambion. Inunación para la vida y la empresa, UPC/EI Comercio, Lima. $2(x) 1$.

19 Sven R. Hed. Manual de plasifficación y control de prosectos. $1981 . \mathrm{sl}$.
}

en el sentido de que se trata de definir la "vida colectiva" en la cual, por más individualista que sea la sociedad presente, se expresan los gestos o prácticas sociales. Por consiguiente, Boltanski retiene la idea de que una sociedad es una civitas, es decir, un conjunto de grupos que se forman en función de prácticas con objetivos más o menos claros, o que el management trata de definir en términos transparentes. Ahora bien, una definición de la "ciudad de proyectos", inspirada en la más reciente literatura de management, apunta hacia una construcción de redes en que las asociaciones de individuos persiguen sus actividades o sus proyectos. Si esa es la tendencia a partir de 1990, la "ciudad de proyectos" emerge de las ruinas de la sociedad industrial y comercial del siglo XIX y de la primera mitad del siglo $X X$. Las consecuencias son importantes y en ellas se puede, desde ahora, detectar la sombra del empresariado como actor transcendental en el proceso de cambio de las sociedades contemporáneas tanto de aquellas que siempre optaron por la economía capitalista cuanto de las que habían hecho la experiencia de la economía socialista o comunista. Veamos:

Primo. Al abandonar al juego del mercado, las reglas de intercambio entre individuos y grupos, las sociedades contemporáneas opulentas optan por un paradigma de conductas que posee una configuración específica, es decir, las que prevalecen en los modos de intercambio económico y financiero. El modelo de conducta es el que el propio mercado impone a la sociedad en general y no el que generan los distintos grupos, partiendo de sus propios intereses. Así, si es el mercado quien genera el paradigma de práctica social, la sociedad pasa a ser el conjunto de individuos que se ofrecen al que más da en una red global. Por lo tanto, es esa la nueva definición de sociedad o civitas que cambia radicalmente la perspectiva sobre el futuro de las sociedades presentes. Profundicemos algo más este punto que está en el centro de las discusiones contemporáneas:

Punto uno. Hurgando entre los autoresgurús del management algunas definiciones significativas, retengamos las de Drucker sobre la "sociedad postcapitalista" que para él es la "sociedad de conocimientos". En ella no son los productos ni el capital los que producen el rendimiento exigido por una empresa capitalista: "Los únicos - o por lo menos los principales - productores de 
riqueza son la información y el conocimiento"20. Más audaz que el viejo gurú es Rifkin. Según él estamos en la "era del acceso", en la "revolución de la New Economy" ${ }^{21}$. Rifkin habla, en estilo casi eufórico, del advenimiento del capitalismo cultural que reemplaza el que hasta ahora nos orientó, al cual Boltanski llamaba "comercial". Así, asistimos a la agonía del viejo capitalismo industrial: "estamos ante un mundo de símbolos, de redes y bucles de retroalimentación, de conexiones e interacción, cuyas fronteras se oscurecen, donde todo lo sólido se desvanece en el aire"22.

Punto dos. Cuando Drucker habla de la sociedad futura y afirma que ella será la "sociedad del conocimiento" dónde el cliente es la pieza clave de la empresa no menciona a donde apunta la relación con el cliente ni las razones por las que ellas deben existir. Según las definiciones de los gurús del marketing la nueva perspectiva o "la revolución de la nueva economía" se basa en el hecho de que la producción no es la clave de la empresa sino más bien lo es la distribución ${ }^{23}$. Y ésta obedece al principio de que el mercado está inundado de productos y por lo tanto hay que convencer al cliente de la importancia del conjunto de servicios que se le pueden prestar en medio de la abundancia. Y para eso sive el marketing, es decir, la forma como la empresa debe organizarse para que las relaciones entre ella y sus clientes ayuden a asegurar las transacciones económicas o financieras en las mejores condiciones posibles para el empresario, es decir, con el máximo de ganancia posible.

Punto tres. Tanto el discurso de Drucker como el de los otros gurús del marketing soslayan la propia razón de ser del mercado que consiste simplemente en el juego de los que se apropian de la fuerza del trabajo, de lo que ella permite alcanzar (productos y servicios) y de los que la venden al precio que mejor se pueda alcanzar dentro de la competencia organizada por el propio mercado. En esa perspectiva, para Drucker, la "sociedad del conocimiento" es la construcción de un mercado donde el conocimiento se vuelve la pieza clave - producto - de las transaccio-

20 Peter Drucker. ap. cii.. Bogotá. 1995: Jw9.

21 Jereny Riskin. La eva del access. La tevolución de la mueva ecomomia. Paidós. Buenos Aires, $2(k)$

22 Jeremy Rifkin. op,cit. Buenos Aires. 20kk): 167. La frax “...toklo lo sólido se desvane ce en el aire" es de Marx y la empléri como título de su libro Marshall Beman. Toto

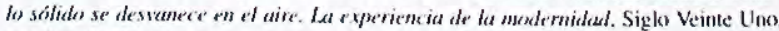
México. $2(k x)$ (sólo se emplea cuandes el original es sealmente antiguo).

23 Peter Drucker, op. cit., Bogotá. 1995: 144-157 nes. $Y$ contrariamente a lo que sugiere, esa "sociedad del conocimiento" tiene algunas expresiones muy antiguas donde se procesaban las reglas de apropiación del saber como base para acceder al poder e imponer a los otros grupos sociales el precio de la relación social. Para no ir más lejos, es quizá el caso de los amautas en el antiguo Perú, los cuales parecen haber existido asumiendo el saber como producto de apropiación del poder y como modo de desempeñar en la sociedad incásica su función de dominio político, pero dejemos a los amautas en paz. En el contexto señalado por Drucker se ha de vender conocimientos en las mejores condiciones posibles del mercado. La empresa compra conocimientos para mejorar sus objetivos los cuales no han variado desde que las prácticas capitalistas existen.

Secundo. Con el desarrollo de ese nuevo paradigma de mercado se quebró uno de los principios más respetados durante un siglo, el del papel del Estado en la construcción de una sociedad más justa y fraterna. El hecho es algo paradójico. ¿Cómo explicar la quiebra del Estado dentro de la sociedad que lo había proclamado su defensor y guía? ¿Qué motivos y razones pueden convencer a los individuos y grupos para abandonar a quien, en teoría, sería su principal aliado? Sin duda, la experiencia histórica de las sociedades socialistas del siglo $X X$ ayudó a convencer a los ciudadanos de la ineficacia de las estructuras estatales y de la necesidad de buscar en el propio individuo la energía que falta al burócrata para transformar la fuerza del trabajo en instrumento eficaz de producción. Los argumentos de Thatchery Reagan en las décadas del 70 y 80 iban por ese lado, es decir, desde el Estado romper con el propio Estado y entregar al ciudadano libre la responsabilidad de generar riqueza, de producir integrado a la ley de demanda y oferta. En otros términos, el individuo se entregaba a la propia ley del mercado cuya finalidad consistía en la producción de bienes y servicios dentro de los cánones de la libre empresa. Y el objetivo de la empresa ya lo conocemos: buscar la mayor rentabilidad y someter a su imperio la fuerza del trabajo. Desde esa perspectiva, el individuo como individuo busca en la empresa el contrato de venta de su trabajo y se somete a la regla de rentabilidad del mercado.

Tertio. En ese nuevo contexto sugerido en el anterior párrafo, el tejido de las relaciones sociales sigue también los procesos que sugieren las nuevas tendencias. Según ellas, y como afirmamos más arriba, las reglas de juego entre individuos se crean y fijan por decisión del propio juego de la oferta y la demanda. Asimismo, no existe la amenaza 
de grupos organizados o clases, porque el propio mercado los disolvió para negociar individualmente las condiciones de compra de la fuerza de trabajo. Boltanski analiza distintas opciones de respuesta a este nuevo género de relaciones sociales. En todas ellas hay dificultades en percibir las nuevas situaciones creadas por la fragmentación de la fuerza del trabajo y por la propia empresa que, aún guardando sus objetivos financieros, requiere de obtener ganancias suficientes para garantizar su futuro ${ }^{24}$. Del choque de intereses, los de la empresa y los del trabajador, en el contexto de una gran movilidad exigida por los que poseen el capital o lo invierten y de las enormes dificultades del trabajador en desplazarse, ha de nacer la propia dinámica de construcción del tejido social. Por lo que se va concretando en distintos escenarios empresariales, el trabajador sale disminuido en la capacidad de obtener mejores condiciones de bienestar y seguridad. $Y$ le falta sobre todo el respaldo comunitario o clasista de las épocas anteriores porque tampoco tiene el Estado para garantizarlos.

Quarto. Estos nuevos procesos sociales, que supo imponer el grupo de sociedades opulentas de Occidente a partir de la experiencia secular del mercado libre, desembocaron en los actuales reordenamientos sociales que Boltanski llama "ciudad de proyectos", en donde la construcción de redes (networks, réseaux) alteró y transformó todo el ejercicio de las relaciones sociales. Señalaré uno o dos puntos que pueden ayudar a comprender mejor lo que se pretende sugerir. Punto uno: la práctica social en red permite conectar individuos cuyo origen y ubicación prescinden de lugar y hasta de tiempo. En ese sentido, la construcción de la red se hace en función de los desarrollos de una empresa que busca doquier los individuos capacitados para ello. Un ejemplo: Miguel Rivera, actual presidente ejecutivo de Nextel en el Perú, es limeño, laboró durante 22 años en IBM y 15, en seis países distintos. Nextel es una de las empresas más importantes de Estados Unidos y está presente en Argentina, Brasil, Canadá, China, Filipinas, México y Japón (El Comercio, 25 de mayo 2001, p. B2). En términos de movilidad geográfica, ese ejecutivo transmite la perfecta imagen de la sociedad actual e igualmente la representa en los objetivos que busca una empresa multinacional. Rivera es un nudo en la

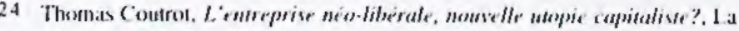
découverte, Paris, 1998.
}

red de una gran empresa que lo puede separar cuando bien le parezca, lo que sucede generalmente cuando el ejecutivo no genera las ganancias previstas. Por las mismas razones y en los mismos términos, la empresa se abastece de fuerza de trabajo en el mercado, es decir, en forma de red.

Quinto. En contra de la movilidad y la circulación cada vez más acelerada exigida por la empresa en red, se levantan varios obstáculos. Algunos de ellos son difíciles de superar por los cambios que exigen en la reconstrucción del tejido social. El caso de la rotación de la mano de obra en una empresa es un ejemplo de ello. El sector empresarial requiere cada día más de mano de obra que se adapte a múltiples formas de trabajo y en muchas circunstancias, exige que el trabajador se desplace de lugar tantas veces cuantas sean necesarias para la producción de la empresa. El incremento de la movilidad geográfica en las sociedades más avanzadas desde el punto de vista socioeconómico es exponencial. Algunos de los sectores como el del traba.jo en las industrias de electrónica, son reconocidos por la volatilidad del empleo. Lo mismo ocurre en otros campos de las nuevas empresas de servicios que recurren a la inmigración para reemplazar puestos de trabajo inamovibles por trabajadores ocasionales. Quizá sea este novísimo campo de las relaciones de trabajo uno de los más agudos y difíciles de resolver. De alguna manera el mismo fenómeno se da en la propia empresa que no puede desplazarse fácilmente. En algunos casos, las pequeñas empresas locales asumen tareas de producción que les otorga la empresa gigante porque, en ciertas circunstancias, las multinacionales no pueden asumir todos los riesgos locales. Ocurre, sin embargo, que la mayoría de las pequeñas y medianas empresas por no poder desplazarse mueren atrofiadas por la invasión de los productos de las grandes empresas y por la competencia que ellas le traen en el área de precios. La consecuencia de todo ello es, entre otras, la de la creación de profundas desigualdades sociales y la de ampliar el foso que separa tanto los países desarrollados de los menos desarrollados como las regiones prósperas de las que se hunden en la pobreza y la miseria.

\section{III.-El empresariado frente a la crítica}

Las perspectivas presentes del empresariado varian según el enfoque que se quiera dar a la organización del trabajo y a los objetivos que los individuos y grupos se proponen alcanzar. Queda 
claro que los cambios ocurridos en las sociedades contemporáneas más desarrolladas nos señalan algunas orientaciones sobre la manera como el sector empresarial enfrenta algunas dificultades en su desarrollo. Revisando, con Boltanski, las lecciones que el siglo XX nos dio en materia de organización empresarial y de sus formas de enfrentar la crítica que muchas veces supo integrar a su propio desarrollo, se pueden distinguir dos campos en que esos enfrentamientos se llevaron a cabo, el social (lucha obrera y campesina) y el artístico (movimientos intelectuales, artísticos y literarios). En la primera mitad del siglo XX, la cohesión de la clase obrera era más estrecha y las corrientes artísticas y libertarias desempeñaron en algunos casos papeles muy importantes para obtener beneficios sociales. Una de esas últimas expresiones fue sin duda el movimiento estudiantil en la década del 60 en Estados Unidos y en Francia. A partir de ahí los cambios que esas luchas anunciaron fueron siguiendo su camino y el medio empresarial supo imponerse a sí mismo la disciplina que le permitía asumir grandes cambios. No los podemos analizar en detalle, pero señalaremos hechos que ayudan a comprender mejor de lo que se trata.

Primo. La crítica social y el entorno histórico. Lo que caracterizó gran parte del siglo XIX y la primera mitad del siglo XX fue la organización de la clase obrera, en medio de dos guerras mundiales y de la construcción del comunismo soviético. La señal de que algo iba cambiando por debajo de la aparente bonanza del desarrollo de las sociedades occidentales y del evidente crecimiento económico de los países capitalistas, salió de varios movimientos que, en sus expresiones más o menos aisladas, se diluyeron en la memoria. Por ejemplo, la primavera de Praga a finales de la década del 60 o mayo del 68 en Francia que despertó a Europa y la sacó de su morna siesta a la sombra de De Gaulle. El choque fue brutal y desde ese entonces nada ha sido igual en la sociedad francesa. Sin embargo, en América del Sur, en la misma década, las dictaduras militares asumieron poco a poco las riendas del poder. $Y$ donde se esperaba una larga y dolorosa transformación social no ocurrió sino la razzia político-militar con fuertes tintes anticomunistas. ¿Quiénes en el Perú no recuerdan la dictadura de Velasco? Su gran reforma social terminó en un evidente fracaso. Luego, en la década del 80 , irrumpen los grupos terroristas que impiden que las fuerzas vivas de la sociedad miren con serenidad el futuro del país. El temor de una catástrofe y el terror que se apoderó de la sociedad civil no permitieron que los individuos y grupos fuesen más allá de las preocupacio- nes cotidianas y de la supervivencia. Hablar en ese entonces de empresa era un suicidio. La experiencia de Alan García terminó en desastre económico y quiebra general del sector empresarial. Y en medio del fracaso, la propia crítica se hundió frente a la presencia cada día más apremiante del terror.

Secundo. Crítica social y fujimorismo. Fujimori no permitió durante diez años que se expresase la voz de la crítica social, admitiendo, sin embargo, que una cierta clase política conservara sus privilegios. La prensa escrita mantuvo la mayoría de sus derechos, porque según consta en el ideario de los analistas políticos, Fujimori era consciente de la corta proyección de la prensa escrita, excepto la de la "prensa-basura", seleccionando para su palco de representación y difusión la televisión y la radio. En términos de reivindicación social objeto de la crítica, la sociedad peruana terminó perdiendo algunos de los avances alcanzados en esa lucha. Claro está, no poseemos aún todos los detalles de la hecatombe del fujimorismo para evaluar la justa progresión del quehacer económico y financiero en los últimos diez años. Sin embargo, la gran mayoría de los analistas se inclinan por la pérdida de peso de lo que se llamaba la clase obrera organizada y la incapacidad de los líderes obreros de reunir las masas para exigir de las autoridades políticas o empresariales una más justa y equitativa distribución de la riqueza nacional.

Tertio. Empresariado y crítica social. Hasta donde se pudo verificar por los números publicados en las estadísticas oficiales del decenio que acabamos de vivir es justo reconocer ciertos movimientos favorables de inversiones que ayudaron el país a seguir por el camino de un crecimiento económico sostenido durante algunos años. A ello contribuyeron la privatización de algunas empresas estatales y la llegada de capitales extranjeros para ciertos sectores de actividad, entre otros el minero. Con la liberación de una parte importante de la mano de obra del espacio público y la tragedia viva de Sendero Luminoso se fue extinguiendo la voz de la critica en el espacio de acción de las prácticas empresariales. En ese sentido, el inicio de la década del 90 fue favorable a la acción política del Perú en el exterior. Fujimori fingió tener la seriedad necesaria para ser acreditado como gobierno honrado y firme. Esa fama que hoy se ha transformado en trágico desencanto permitió que la crítica social se desvaneciera. El sector empresarial vió siempre con buenos ojos la seguridad que le ofrecia el gobierno de Fujimori. Por eso desperdició una ex- 
celente ocasión para sacar algunas lecciones que las sociedades más avanzadas iban tomando de su propio desarrollo.

Quarto. La crítica artística en ruinas. Si la crítica social sufrió el impacto de las prácticas dictatoriales de Fujimori, la crítica artística se hundió en una modorra de la cual empezó a despertarse en las postrimerías del desastre fujimontesinista. Cuando eran evidentes las maniobras políticas fraudulentas y la magnitud de la gestión corrupta, se levantaron de la sombra los artistas y una parte importante de la juventud. Esa gesta tardía nació en medio de una crítica general a la dictadura y a sus prácticas dolosas. Por consiguiente, le faltaba la ingenuidad de los movimientos espontáneos y la agresividad de los gestos carismáticos avasalladores. Sin embargo, en medio de dudas y lecturas vagas de los hechos, puede afirmarse que en los últimos dos años se levantaron y salieron a lucir algunos de sus genuinos pergaminos y lograron alcanzar algunos éxitos importantes. "Lavar la bandera" fue uno de esos gestos típicos de la crítica artística tanto como la participación en la Marcha de los Cuatro Suyos, dando un toque de gracia y de poesía a la protesta más auténtica y espontánea que hemos vivido en los últimos años.

Quinto. El empresariado y la crítica artística. Fue, sin duda, un problema que no se planteó en el último decenio de vida social peruana, el de la crítica artística frente al empresariado. Hubo, sin embargo, algunos bostezos que podrían atribuirse a la prolongada somnolencia dictatorial. $Y$ uno de ellos se refiere precisamente a la reivindicación del patrimonio. E' vaso de Machu Picchu es a todas las luces la expresión más clara de esa crítica. Muchos intelectuales se asomaron al balcón para aplaudir la protesta contra la construcción del teleférico. Hace pocas semanas el actual gobierno de transición de Valentín Paniagua acabó por dar oídos a la crítica y negó el permiso de operación del teleférico. Claro está el objetivo de esa acción de protesta alcanzó el proyecto de la empresa hotelera que promovía un mayor desarrollo turístico de las llegadas a Machu Picchu. Puede ser que otros casos se planteen en el futuro ${ }^{25}$.

\section{IV.-El discurso del management como ideología empresarial}

Profundizando más las razones que deben dar cuenta de la existencia de un amplio consenso en torno a la aceptación de las prácticas económi- cas inspiradas en las doctrinas que defienden la acción libre y soberana del mercado, conviene echar mano de la literatura publicada en torno al modo como se debe de proceder en la construcción de la empresa y luego en la conducta cotidiana que ella debe desarrollar para alcanzar sus objetivos. Los mentores o, como le llaman los entendidos, los gurús son muchedumbre. Para el profano tienen la ventaja de identificarse por sus diplomas académicos y sus éxitos profesionales. Como lo recordé más arriba, un gran número procede de Estados Unidos y también de Inglaterra. Transmiten una palabra que posee algo de magia. Inculcan en los auditorios un misticismo que bordea la más irracional de las prácticas sociales. Por eso, no faltan, en la mismísima plaza norteamericana e inglesa, violentas voces críticas de los fundamentos teóricos y éticos del management. Thomas Frank es uno de ellos ${ }^{26}$.

Lo más interesante del caso es que Frank complementa muy bien el enfoque de Boltanski. El americano pasa revista a la más reciente literatura del management y recorre los senderos que los gurús toman para dar a conocer las nuevas tendencias y sus más recientes pensamientos acerca de la orientación de las fuerzas económicas y financieras. Huelga decir que es un vasto y amplio sector de la vida estadounidense y que un periódico muy conservador como The Wall Street Journal, editado parcialmente por El Comercio (Lima) y otros periódicos de América Latina, lo ejemplifica perfectamente. Por consiguiente, apenas me atrevo a señalar algo que muy superficialmente incide sobre los propósitos que desarrollo: Frank da cuenta de la profunda renovación del discurso managerialy de la vasta operación publicitaria que él creó para difundirlo. Desde los años 90 es clarísima la batalla de los conservadores americanos y británicos para garantizar que el ideal de la sociedad contemporánea esté en la poderosa imagen del libre mercado, paradigma del futuro de la Humanidad: "The world is ruled not by politicians but by markets", escribia el director de The Wall Sreet Journal. Y como líder en la construcción y difusión del discurso ideológico económico y financiero más conservador, Bartley y sus colegas acusan a los crí-

\footnotetext{
25 Rifkin recuerda en un otro contexto el caso de Greenwich Village de Nueva York en los años 1920 donde los anistas bolzemios criticaban los principios austeros de la ética protestante. $Y$ el guni det management hace un comentario ingenuo pero muy significativo: la critica artística sirvis adecuadamente los intereses del capitalismo porque en ese entones la economía americana pugnaba por pasar "de un modo de producción a otro de consunto". Jeremy Ritkin. op. cir., Buenos Aires, 20X0): 193. 26 Thomas Frank, op. cit.. NY. 2000)
} 
ticos del capitalismo irrestricto de elitismo. La idea es interesante por lo que representa en el tablero ideológico de la década pasada y por la popularidad que ganó en todo el mundo. Conviene explicarla para que no haya confusiones.

Para la New Economy que difundieron todos los medios adictos al conservadurismo político, que en los Estados Unidos se reagrupan en torno al Partido Republicano y a ciertas instituciones financieras, el elitismo no está en los modales de los "nuevos ricos" prendados por el mercado, donde imperan las más grandes virtudes, verbi gratia, la "modestia democrática", la humildad frente a "la voluntad popular". Para este sector importante de las sociedades americana y británica, la prosperidad es el producto del propio mercado que, como la "voluntad divina", elige sus mensajeros y los premia con la riqueza y el bienestar. Al contrario, las "élites" son los dirigentes sindicales, los funcionarios-expertos que dictan las normas para dar agilidad y viabilidad a los sistemas de seguro social, los políticos que defienden el papel del Estado en la distribución de la riqueza nacional. Eran esas clases dirigentes que recibieron los ataques feroces de las primeras páginas del economista austriaco Hayek en The Road of Serfdom (1944) y en The Fatal Conceit (1988). Se recordará la comparación que estableció entre los socialistas británicos y la obscenidad nazi. Para Hayek, siempre existió una dictadura de la clase intelectual que jamás ahorró palabras para destruir a los que se entregaban a actividades financieras y a las "leyes infalibles" del mercado. Son esos críticos que ocupan las jerarquias sociales y se atribuyen a sí mismos distinciones que no merecen. Uno de los más cercanos consejeros de Ronald Reagan definía "populismo" como una abstracción moral que consiste en la actitud optimista frente a la capacidad del pueblo de tomar las decisiones que más convienen para su propia vida. Al contrario, el elitismo está en aquellos que se sustituyen al pueblo para luego imponerle sus valores y normas $^{27}$. Por consiguiente, creer en el populismo, concluía Jeffrey Bell, es creer en el libre mercado ${ }^{28}$.

No faltan argumentos a Frank para comparar estas actitudes con el desarrollo ideológico que desde el siglo XIX caracterizó a los Estados Unidos y la lucha sin cuartel entre la clase obrera y el empresariado. Sin embargo, en la pasada década, que alargaba hasta la entrada del milenio el discurso ideológico de Reagan en las barbas de la experiencia de Clinton, algunos autores ganaron fama por la difusión de un discurso que relacionaba en forma categórica el mercado y la democracia ${ }^{29}$. Así como la discusión entre elitismo y populismo en el contexto de afirmación de la New Economy reconstruía un vocabulario en que los términos se empleaban adulterando las definiciones corrientes de los mismos, también en el caso del vocablo "democracia", los gurús se preocuparon por redefinirlo y redimensionarlo..$^{30}$ Uno de los más destacados especialista del management, Peter Senge, explica que ese viejo término de la ética clásica y luego del pensamiento político, poco o nada tiene que ver con la "igualdad, justicia, o la mayoría de votos". Para él, la democracia designa lo mismo que define el mercado, la humildad. En su The fifth discipline trata de convencer al lector de que las nuevas corrientes de pensamiento managerialvan por ese cauce, donde el diálogo debe prevalecer sobre la imposición autoritaria. La humildad es "live in a continual leaming mode" ${ }^{31}$. Y en otro reciente estudio, The dance of change, insiste de nuevo sobre la importancia capital de esa actitud de espíritu, donde el manager se siente bien porque escucha y comparte su opinión con los "otros", o porque el "otro" puede aportar valiosas soluciones a muchos problemas.

\section{V.-La postmodernidad en el empresariado peruano}

Le nouvel esprit du capitalisme hace referencia a un tema recurrente en el pensamiento de Boltanski: los grupos sociales no se constituyen sino por la capacidad que tienen para definirse ${ }^{32}$. Ese principio es uno de los más genuinos en términos de la tradición clásica de la sociología. De hecho, sin el discurso que los sustenta, la "clase obrera", la "clase burguesa", la "clase dominante", no son sino abstracciones sin contenido real, histórico. Igualmente no existirían los otros grupos sociales en que se fueron fragmentando los "clásicos", verbi gratia, los obreros reunidos bajo el techo del discurso de la dominación y de la explotación. O sea, durante un siglo, la "conciencia obrera" ope-

\footnotetext{
27 Thomas Frank, op, cis. NY, 2000.

28 Thomas Frank. Hiilem.

29 En el Perú se ha hecho famosa la pesición ideológica de Mario Vargas Llusa que defendia los principios de libre mercado como tundamento de la democracia.

30 Thomas Frank. Hidem.

31 Cit. Por Thomas Frank. op. cit.. NY. 2(KK). 208

32 Luc Bollanski. Les cadres. La formation d'un grougle social, Minuit, Paris, 1982
} 
ró como elemento de integración de las fuerzas vivas de la sociedad industrial y supo sacar provecho de su expresión ideológica para asumir un papel histórico que todos le reconocemos. Asimismo, como lo subraya Boltanski, el capitalismo evolucionó en el sentido de aprovechar de sus propios excesos y errores para llegar al inicio del milenio con evidentes ventajas sobre cualquier otra propuesta de práctica socioeconómica. En ese sentido, lo que constatamos es la producción de un discurso que renovó de cabo a rabo su estrategia y pudo recrear la "nueva clase", o afirmar la New Economy. Ese es el hecho fundamental de la segunda mitad del siglo XX.

En la línea de lo que nos sugiere Boltanski, cabe entonces preguntar si entre los cultores del managementen el Perú existe la idea de formar un cuerpo institucional claramente constituido. Por ello, no sería del todo descabellado aprovechar los restos para preguntarse también si la conciencia managerial existe en la sociedad peruana o es simplemente el eco de olas producidas en otras partes del planeta. En las anteriores páginas, hemos referido algunas manifestaciones tanto académicas como empresariales donde se vienen ventilando algunos de esos temas. Recordémoslos: ESAN, IPAE, la Universidad del Pacífico, la UPC. Los encuentros anuales de CADE han sido ampliamente celebrados. Y finalmente la publicación de algunas obras distribuidas al gran público por El Comercio, ayudaron a llamar la atención sobre estos asuntos ${ }^{33}$.

Dentro de los cuerpos empresariales, no mencionamos hasta ahora algunos grupos, verbi gratia, Confederación de Empresarios Peruanos (CONFIEP) y Sociedad Nacional de Industrias (SNI). Una y otra representan intereses económicos y financieros importantes. Últimamente, como es de conocimiento público, CONFIEP no supo guardar en sus filas algunos sectores por desacuerdos con la nueva directiva, lo que demuestra la debilidad del grupo en términos de intereses de "clase" y la evidente falta de un discurso coherente que le sirva de sustento. En ese sentido, la hipótesis de Boltanski sive para señalar que probablemente CONFIEP no represente a un grupo propiamente dicho sino a individuos o empresas más o menos fragmentadas. Por consiguiente, no sólo esa institución carece de fuerza de presión junto a otros organismos, sino que también adolece de una clarísima ausencia de producción del discurso que la transformaría en "conciencia" de grupo. O quizá sea ese hecho algo insólito, la expresión de una fragmentación discursiva que correspondería más a una "conciencia" de cor- te postmoderno que a una "conciencia capitalista" más cercana a lo que se entiende, en términos filosóficos e históricos, por modernidad. Exploremos esta veta. Vamos por partes.

Acercamiento uno. Montalbetti, de la Escuela de Empresas de la UPC, comentaba en un artículo lo que va ocurriendo en el mundo empresarial y subrayaba el hecho de que las "empresas top" cambian rápidamente de posición y muchas desaparecen en cortos períodos. Ese hecho puede ser debido a varias causas. Sin embargo, en el contexto de mercado, no cabe la menor duda de que una de las razones de ese sorprendente hecho es lo que se conoce con el nombre de "globalización". Y dado que la norma de existencia de la empresa en un contexto capitalista es competir con otras, un gran número no resiste ni a la competencia ni a los esfuerzos que despliegan los competidores para derrumbarla. El contexto es de fragmentación en el sentido en que la "individualización" es necesaria para encontrar "el nicho" donde posicionarse y ejercer su práctica económica y financiera. $Y$ todo el discurso que sostiene esa práctica es precisamente el del ejercicio individual del éxito dentro del mercado global que no perdona a los que olvidan que se trata de competir. En suma, la empresa definida en los manuales de managementy en los consultores empresariales, es la isla en que se refugia el competidor y de donde él sale para atacar al que se acerca e intenta compartir su espacio vital.

Acercamiento dos. Entre los autores que venimos comentando y los que representan en los Estados Unidos e Inglaterra gran parte del top management, existe un discurso que cabe perfectamente en los moldes de lo que se entiende por postmodernidad. Lo mencionó Frank en su One market under God. En términos más concretos, se expresa ese discurso con visos de excéntrica controversia y enorme publicidad. Recuérdese el tema del "canibalismo". Conél, por ejemplo, queda de manifiesto la intención de "escandalizar" y atraer la atención del empresario hacia un género de valores que infringe las normas comunes y corrientes. De hecho, con ello el discurso del managementcomo ideología del empresariado recurre a un conjunto de símbolos de origen diversoe indiferente a la cohesión que caracteriza los antiguos lenguajes del

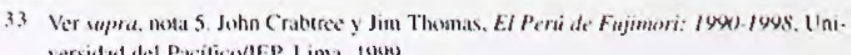
sersidas del Pacilicu/IEP. Lima. 10y) 
capitalismo. No lo menciona Frank. Sin embargo, una de las razones que explicarian esa tendencia postmodernista sería precisamente la de hacer frente al pensamiento crítico, máxime al de la crítica artística, como la había definido Boltanski.

Acercamiento tres. Mucho más próximo a la realidad social latinoamericana que Frank y Boltanski se muestra el libro de El postmodernismo en la empresa de Carlos Llano, donde no faltan algunos ejemplos empresariales que son para él el modelo de la concepción postmoderna de empresa. Por los ejemplos que emplea, su experiencia es mexicana. Sin embargo, su propósito es eminentemente académico no sólo por los autores que cita sino también por el esfuerzo que despliega para introducir en el ámbito del pensamiento empresarial la idea de postmodernismo. Aunque para Llano, las cosas se presentan relativamente fáciles - la empresa contemporánea obedece al paradigma general del pensamiento postmodernista - para una lectura un poco más crítica, tanto de los autores que él selecciona como por la forma como se apropia las nociones teóricas, plantean no pocas dudas. Discutiremos algunas porque se ubican en el corazón del presente debate.

Primera duda. Llano emplea una distinción entre modernismo y postmodernismo que no corresponde a las discusiones que una visión más histórica y rigurosa maneja desde el siglo XVIII hasta nuestros días. Claro, habrá muchas opiniones que le dan razón. Sin embargo, si se trata de los que tienen voz y pontifican en ese campo, las orientaciones tienen su norte y se desplazan en sentidos bien definidos ${ }^{34}$. En ese orden de ideas, el empleo que hace de esos dos términos es algo engañoso porque esas dos palabras definen campos hermenéuticos algo distintos a los que sugieren sus comentarios. Concretamente: modernismo y postmodernismo evocan los hechos artísticos y movimientos literarios, no tanto concepciones teóricas y pensamientos epistemológicos planteados por la llustración del siglo XVIII. Por consiguiente, sería preferible emplear un vocabulario más preciso, por ejemplo, usando las dos nociones centrales de la discusión, la de modernidad y la de la postmodernidad ${ }^{35}$. Tiene razón Llano al escribir que Habermas defiende la idea de que la modernidad es un proyecto inconcluso y que durará aún muchas décadas antes que sean satisfechas sus reivindicaciones fundamentales. Compartimos con él esa opinión.

Segunda duda. La evocación de la Lebenswelt o mundo de la vida es interesante en el contexto de la ideología empresarial y managerial. Sin embargo, su reflexión sobre ese punto me parece contrariar el sentido profundo que le da la perspectiva metodológica de algunos autores, entre ellos Habermas. A mi modo de ver, la Lebenswelt es el primer nivel de construcción de una visión general de la sociedad. Así lo han expresado algunos autores y hasta "escuelas" como, por ejemplo, la de etnometodología. Si Llano hubiera leído más atentamente Habermas no se le escaparía la idea. Y si conociera mejor la literatura sociológica y antropológica americana presentaría algunos ejemplos que le ayudarían a plantear correctamente algunos de los problemas que se plantean las empresas ${ }^{36}$.

Tercera duda. Según Llano, "las manifestaciones típicas del postmodernismo" son: el ecologismo, el feminismo, el pacifismo y el nacionalismo. Si el autor no añadiera al conjunto la palabra "nacionalismo", hubiéramos creído que se trataba de fenómenos sociales contemporáneos. Al añadirle el "nacionalismo", Llano confunde hechos específicos de la sociedad contemporánea con expresiones más añejas de la revolución ilustrada. El ecologismo, feminismo y pacifismo no son "postmodernos" y el nacionalismo mucho menos. Aquellos son movimientos contemporáneos oriundos de la revolución ilustrada y de lo que Boltanski llamaría la "crítica social"; ésta es la expresión más cercana a una afirmación de la Tradición en el ámbito de la modemidad, o sea todo lo contrario de lo que afirma Llano. ¿Qué conclusiones saca Llano de sus propios errores para su concepción de la empresa? De hecho, muchas. Sin embargo, pocas tienen algo que ver con la postmodernidad. El estilo es de moraleja. De postmoderno poco o nada tienen.

Cuarta duda. Lo que subraya Llano es la imprescindible necesidad de imponer en el ambiente empresarial unas cuantas "virtudes" o "hábitos" que transformarían la empresa en experiencia de vida. En un entorno de "amistad", de "confianza", de "honestidad", los encargados de definir y activar la empresa han de emplear el máximo de energías para que ella alcance sus objetivos. Y claro está, esos objetivos son los que todos conocemos: maximizar las ganancias. Si es así, lo que Llano parece confundir es la existencia de la empresa con algunas

\footnotetext{
34 Jurgen Habermas. El discurso filesófico de la medernidad. Taurus, Madrid, 1989; Fredic Jameson, Teoria de la posmodernidad. Trotta, Madrid, 1996: Niklas Luhmann. Complejidad y modemidad. Trotta. Madrid. 1998.

35 Henrique Urbano, Comp.. Modernidad en los Andes. CBC. Cuzco, 19991: IX-XV: Henrique Urbano. Comp.. Tradición y modernidad en los Andes. CBC. Cuzco, 1993.

36 La literatura a que hacemos referencia es la de la escuela antropológica de Oscar Lewis con su clásico libro sobre Los Hijos de Sánchez. De igual manera. I etnometodología que acabo de referir y la excuela de Garrinkel.
} 
manifestaciones de la cultura contemporánea. Si éstas son o no expresiones de postmodernismo es asunto que merece ser discutido. Queda por averiguar el peso que ellas puedan tener en la concepción de una organización de corte empresarial, porque los "hábitos" o "virtudes" que describe nos recuerdan no tanto la sociedad contemporánea cuanto la Edad Media.

Quinta duda. El contraste entre postmodernidad y modernidad no se expresa con las nociones que Llano emplea, las cuales provienen de un contexto axiológico con manifiesto sabor a "prédica evangélica americana" para emplear una imagen que Max Weber no desecharía. Se caracteriza esa "palabra moral" por un llamamiento del público hacia los valores que deben guiar la sociedad. Son generalmente "virtudes", como escribe Llano, las cuales aseguran a las masas, la seguridad, la confianza, la esperanza. Lo que se llamó hace años la Iglesia TV, es decir los programas televisivos de los grupos evangélicos americanos, no se cansaban de difundir ese tipo de principios en los miles de millones de teleespectadores. Le añadían música y algunos "milagros" para impactar y convencer. ¿Tendrá el contenido ideológico de esos grupos religiosos algo que ver con el postmodernismo? Lo dudo mucho. Pero, sí, no es indiferente a ciertos géneros de orientaciones ideológicas empresariales. ¿Cuál será en el Perú el peso de esa perspectiva empresarial? Difícil de contestar porque no se han llevado a cabo estudios sobre el tema. Sin embargo, los grupos evangélicos reunidos en una asociación que apoya a ciertos grupos políticos son probablemente la expresión de intereses empresariales arraigados en sectores de corte más popular o de Pequeña y Mediana Empresa (PYMES).

\section{VI.-Conclusión}

De las perspectivas que abrieron las lecturas que nos sirvieron de muleta para entrar en los meandros de la reflexión empresarial, retendríamos la de la dispersión del discurso ideológico del management en el contexto empresarial peruano. En términos más precisos, diríamos que los recursos teóricos del management se refugian en un espacio de la presente sociedad peruana muy estrecho. Pocos son los que lo emplean y los que lo difunden se congregan en eventos que carecen de una sólida orientación institucional y académica. Nos atreveríamos a afirmar que se trata de un espacio social disperso donde compiten voluntades y proyectos individuales.
Carecen de conciencia de grupo y se refugian en "nichos" ideológicos poco consistentes y precarios.

Frente a la fragilidad de la conciencia empresarial peruana, los individuos o empresas recurren al Estado para rogarle que garantice lo que ellos mismos son incapaces de producir, es decir, su propia capacidad de creación de la conciencia de grupo. Es la típica actitud del empresario-rentista. En esos círculos, las relaciones sociales prevalecen sobre el accionar de la empresa. Aunque existen excepciones. Sin embargo, la necesidad de "colgarse" del Estado expresa la inseguridad de los que, por otro lado, reclaman independencia y regalías. Las contradicciones son flagrantes.

Entre todos los elementos que entran en juego en la dinámica empresarial de la sociedad peruana contemporánea los más difíciles de sopesar son precisamente los que se refieren a la evolución tanto de la crítica social como de la crítica artística, para emplear una vez más las expresiones definidas por Boltanski. De las señales que nos dan las prácticas sociales en medio de las hecatombes físicas y políticas que se sucedieron en los últimos años, se pueden aislar algunas, siendo las de la lucha anticorrupción las más significativas. Sin embargo, son ellas también las más difíciles de leer $\mathrm{o}$, si se quiere, de comprender en el sentido weberiano del término. ¿Qué impacto tiene la crítica social y artística en el desarrollo de una sociedad en que las condiciones socioeconómicas de pobreza afectan a 18 millones de personas? ¿Qué sentido dar a las funciones empresariales en una estructura socioeconómica tan frágil? A estas preguntas se responde, regla general, con argumentos muy superficiales, recordando lo que ocurrió con la experiencia capitalista en las sociedades opulentas. Sin embargo, queda por ver si el destino de las funciones empresariales es el mismo en una sociedad tan poco desarrollada como la peruana ${ }^{37}$. No es descabellado pensar que pueda ser diferente.

Henrique Urbano Instituto de Investigación

Facultad de Turismo Universidad de San Martín de Porres Lima, Perú ogil@fccsmp.edu.pe

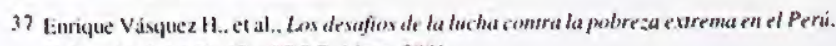
Universidad del PatilicedIDRC. Lima. 2(0)I.
} 